\title{
INTRODUCTION TO BIOTERRORISM RISK ASSESSMENT
}

\author{
Ran D. Balicer and Itay Wiser ${ }^{2}$ \\ ${ }^{1}$ Ran D. Balicer, MD, MPH \\ Epidemiology Department, Faculty of Health Sciences, Ben-Gurion \\ University of the Negav, Beer-Sheva, Israel \\ ${ }^{2}$ Itay Wiser: MD. Department of Epidemiology and Preventive \\ Medicine, School of Public Health, Sackler Faculty of Medicine, \\ Tel Aviv University
}

\section{Pre-event}

\subsection{WHY HAS BIOTERRORISM NOT BEEN USED SO FAR TO PROMOTE POLITICAL AGENDAS/VIEWS?}

A quantitative risk assessment depends on there being some reliable data available to the analyst. A quantitative bioterrorism risk assessment would need data or well-informed judgments on the intent of terrorist groups or individuals, their technical capabilities, the attributes of pathogens or toxins that might be used in a biological attack, target characteristics, and the occurrence (frequency) of various attack scenarios. While data regarding target and bioagent characteristics are available, to a lesser or greater extent, data on bioterrorist intent and the frequency of different types of attacks are just about nonexistent.

This data gap apparently stems from the rarity of bioterrorist events and the need to better understand the motives of the terrorists themselves. To illustrate, a search of the Center for Nonproliferation Studies (CNS) weapons of mass destruction (WMD) terrorism database, which is the largest unclassified one of its kind, revealed that out of 383 incidents in which biological, chemical, nuclear, or radiological agents were used by criminals or terrorists during 1900-2001, only 77 biological "events" (i.e., episodes involving the deliberate use of a biological agent to harm people) were perpetrated. Of these, just four post-1945 events generated more than 10 casualties [1].

The successful implementation of a bioterrorism act would require the achievement of several critical steps by the terrorist: acquiring precursor virulent biological seed cultures, growing biological agents in culture, 
process the agents into a form that can be effectively disseminated, improvise an agent delivery device, and carry out the dissemination effectively to cause mass casualties [2]. Even when the appropriate motivation for such an attack exists, an actual effective attack can only be carried out once each of these obstacles has been overcome. Obtaining the appropriate microorganism to initiate an event requires access, as well as knowledge. Restrictions in distribution of potential bioterrorist agents have reduced such accessibility. In addition, the most appropriate strain must be selected. It is speculated that one reason for the lack of success at disseminating anthrax by the cult Aum Shinrikio was the inadvertent selection of a nonpathogenic strain of Bacillus anthracis [2].

Reviewing small portions of the peer-reviewed literature of the past several years, authors have found numerous articles that might be considered useful to would-be bioweaponeers. Published advances in the life sciences that arguably have dual-use applications can be found in many diverse fields, including directed evolution; studies of the mechanisms of virulence in viruses and bacteria including human, animal, and plant pathogens; gene therapy technology; aerosol technology; bio-manufacturing; and so on. Efforts are made to limit the available data on bioterrorism agents in the literature, which may be used by terrorists in their attempts to produce agents of bioterrorism [3]. Yet some authors claim restrictions are already too restrictive, and may have adverse outcomes [4]. Efforts to monitor comprehensively all bioscience research that has potentially destructive applications would subsume huge swaths of science, gravely tax civilian research resources, and could discourage scientists from pursuing advances in fields important to medicine and agriculture, fields we urgently need to advance in order to address the grave vulnerabilities currently imposed by bioweapons [3].

Some authors further believe we grossly overestimate the importance of the threat of bioterrorism. They point out that we must recognize a conflict of interest exists, and that it is an important, though often neglected, element in public health priority setting. They compare these to the conflicts of interest in prevention of the health consequences of tobacco use or of environmental pollution, such as the desire for profit through the provision of equipment, supplies, or consultation, for prestige through the public, visible role in prevention or preparedness, and for power though participation in planning and execution of prevention or preparedness programs. The enormous federal investment in bioterrorism preparedness in the United States has generated enormous profit, prestige, and power to those who engage it [5]. 


\subsubsection{Do we really believe "they" have the capabilities to execute an attack using anthrax, smallpox?}

Most authors believe the risk of a smallpox attack is fairly low. The known supplies of variola virus are limited, rogue states with the virus would probably fear "boomerang" effects or devastating retaliation, and terrorists are unlikely to be capable of successfully handling a lethal mammalian virus [6].

Examining the 2001 anthrax events in hindsight, it appears that neither the targets of attack, nor the person or group responsible for attacks, could have been predetermined by any known prediction methodology. When scientific knowledge about probabilities is absent, thinking about possible outcomes takes on a particular significance [1,7].

One suggested partial remedy for such lack of data regarding the intent and ability of the perpetrators to perform an act of bioterrorism, can therefore be vulnerability analysis. A vulnerability analysis seeks to identify a valuable asset (i.e., a target) at risk of a bioterrorist attack and to conceptualize various ways in which it is vulnerable to such an attack (i.e., various attack scenarios). Accordingly, what might have been predicted in the case of anthrax was that the US mail system could not only be used as a means to deliver anthrax, but also that a letter containing anthrax spores could spread spores among mail workers and to other recipients of mail besides the intended victims, through transfer of spores from the original letter to other pieces of mail. Zilinskas and colleagues further detail these concepts in their summary of a workshop on Bioterrorism Threat Assessment and Risk Management [1].

\subsection{CAN THEY REALLY SPREAD THESE AGENTS EFFECTIVELY?}

Most biological agents (especially type A) are most effectively used as an aerosol. Effective delivery of an aerosolized agent requires that the particle size be $1-10 \mu \mathrm{m}$ to be able to reach the terminal bronchioles and alveoli. Successful aerosol dispersion of a biological agent is also inherently dependent on the environmental and meteorological conditions.

Models calculating the number of casualties inflicted by an aerosol attack have ranged in hundreds of thousands to the millions. Theoretically an aircraft dispersing $100 \mathrm{~kg}$ of anthrax over a $300 \mathrm{~km}^{2}$ area could cause three million deaths in a population density of 10,000 people per $\mathrm{km}$. Aerosolized botulinum toxin has been estimated to decay at between $1 \%$ and $4 \%$ per min, depending on the ambient temperature. At a decay rate of $1 \%$ per min, substantial inactivation ( $\geq 13$ logs) of toxin occurs by 2 days after aerosolization. In the case of plague, the major shortcoming is that it is inactivated by 
sunlight. On the other hand, unlike anthrax and botulinum toxin, it is capable of being transmitted from person to person. However, as evidenced by the recent anthrax letters of 2001, aerosolization of an agent via a plane or machine may not be needed to strike fear and uncertainty among the public [8].

Dissemination of a category A biological agent through the contamination of food and water is considered less likely as most category A agents are not effectively transmitted via food and water. Although category B agents can be transmitted by these routes, they usually cause only short-term vomiting and diarrhea, with a relatively quick recovery. Present public water treatment methods, as well as the boiling of water and cooking of food, are highly effective in neutralizing many biological agents. Contaminating a water or food supply effectively would require large amounts of toxin and bacteria to overcome any dilution factor. However, a recent study warns of the United States' vulnerability to such an attack based on very centralized food processing and distribution methods over large areas. Likely agents are botulinum toxin, Salmonella, Shigella, Escherichia coli, and Vibrio cholerae. The proposed use of botulinum toxin to contaminate a public water source is of questionable efficacy as the amount of botulinum toxin needed to effectively negate any dilution factor would be enormous, as well as the fact that it is naturally deactivated in fresh water within 3-6 days and within 20 min of standard water treatment. In terms of contamination of a food supply, it should be noted that the toxin is inactivated by heating food to $85^{\circ} \mathrm{C}$ [8].

Infection via contact of intact skin with any of the agents is unlikely to result in casualties. However, if the skin integrity is compromised, the potential for disease exists. The recent anthrax letters resulted in 11 cases of cutaneous anthrax causing significant disruption and fear in postal services and mail handlers. Current studies suggest that thorough washing with soap and water is sufficient to overcome even this threat. Currently, with the exception of anthrax, none of the category A agents have environmental stability after release, especially outdoors [8].

Table 1 summarizes the dissemination techniques employed so far in bioterrorism events [2].

TABLE 1. Dissemination techniques employed [7]

\begin{tabular}{lcccc}
\hline Type & Terrorist & Criminal & Other/uncertain & $\begin{array}{c}\text { Total } \\
\text { incidents }\end{array}$ \\
\hline Aerosol dissemination & 2 & 0 & 0 & 2 \\
Direct injection/topical & 6 & 10 & 0 & 16 \\
$\quad$ application & 1 & 20 & & 22 \\
Contaminated food & 4 & 0 & 1 & 6 \\
Contaminated water & 0 & 1 & 1 & 2 \\
Insect/natural vectors & 10 & 13 & 79 & 102 \\
None & 5 & 10 & 2 & 17 \\
Unknown & 28 & 54 & 85 & \\
Total cases & & & & \\
\hline
\end{tabular}




\subsection{REGARDING SMALLPOX: WHAT NEW EVIDENCE WOULD JUSTIFY, ACCORDING TO CURRENTLY ACCEPTED MODELS AND ESTIMATES, PRE-EVENT VACCINATION OF THE WHOLE POPULATION OR SPECIFIC SUBPOPULATIONS?}

The most important risks associated with pre-event smallpox vaccination program are the adverse events associated with significant morbidity and those for which there are no screening criteria to reduce risk. On the basis of these criteria, post-vaccinial encephalitis and the newly appreciated cardiac complications, especially myopericarditis, are of greatest concern [6].

The risk-benefit ratio associated with pre-event smallpox vaccination program would depend on several factors, including mainly the probability for an event and the potential impact of the event, which in turn is largely determined by the site attacked and means of dispersion. One stochastic model, for example, has shown pre-event vaccination of health-care workers proves lifesaving if the probability of a building attack exceeded 0.22 or if the probability of a high-impact airport attack exceeded 0.002 . However, from a national policy standpoint, at the "breakeven" thresholds, the policy implications of vaccination are not equivalent to the policy implications of forgoing vaccination. Forgoing prior vaccination means risking higher losses in an attack for a high probability (for instance 0.78 ) that there will be no attack and no deaths. In contrast, instituting prior vaccination ensures that losses will be lower, should an attack occur, but requires acceptance of the certainty of many vaccine-related deaths and considerable morbidity [9].

The authors of the above-cited model endorsed in their conclusions "a policy of vaccinating all eligible health care workers and first responders before an attack." They assumed that these workers would accept the "risk of personal harm for the public good" and would volunteer to get vaccinated, which has turned out not to be the case. If civilian medical care and public health workers were reluctant to get vaccinated in the face of a much smaller risk of post-vaccinial encephalitis, will they be less reluctant and volunteer in the face of an additionally recognized myopericarditis risk of 1 in 1,800 ? [6]. 
TABLE 2. Direct risks and benefits of pre-event smallpox vaccination before and after a smallpox outbreak [6]

\begin{tabular}{|c|c|c|c|}
\hline Perspective & $\begin{array}{l}\text { Risks realized before } \\
\text { an outbreak }\end{array}$ & $\begin{array}{l}\text { Benefits realized } \\
\text { before an outbreak }\end{array}$ & $\begin{array}{l}\text { Benefits realized after an } \\
\text { outbreak }\end{array}$ \\
\hline \multirow[t]{2}{*}{$\begin{array}{l}\text { Individual } \\
\text { Individual } \\
\text { (vaccinees) }\end{array}$} & $\begin{array}{l}\text { Severe adverse } \\
\text { reactions, including } \\
\text { death }^{\mathrm{a}}\end{array}$ & \multirow[t]{2}{*}{$\begin{array}{l}\text { Psychological benefits } \\
\text { ("peace of mind," } \\
\text { sense of contributing } \\
\text { to public good) }\end{array}$} & \multirow[t]{2}{*}{$\begin{array}{l}\text { Protection against smallpox, } \\
\text { including death }\end{array}$} \\
\hline & $\begin{array}{l}\text { Employment risks }{ }^{\mathrm{a}} \\
\text { Financial risks }^{\mathrm{a}}\end{array}$ & & \\
\hline $\begin{array}{l}\text { Contact } \\
\text { (e.g., } \\
\text { patient) }\end{array}$ & Contact vaccinia $^{\mathrm{b}}$ & None & $\begin{array}{l}\text { Protection against smallpox } \\
\text { from vaccinated contact }\end{array}$ \\
\hline \multirow[t]{6}{*}{$\begin{array}{l}\text { Population } \\
\text { Public } \\
\text { health and } \\
\text { medical } \\
\text { sectors }\end{array}$} & \multirow[t]{6}{*}{$\begin{array}{l}\text { Contact vaccinia } \\
\text { (low risk) }^{b}\end{array}$} & \multirow[t]{2}{*}{$\begin{array}{l}\text { Increased } \\
\text { preparedness, practice, } \\
\text { and readiness from } \\
\text { administering the } \\
\text { vaccine and running } \\
\text { vaccination clinics }\end{array}$} & Prevaccinated vaccinators ${ }^{\mathrm{d}}$ \\
\hline & & & $\begin{array}{l}\text { More efficient and timely } \\
\text { mass vaccination campaign }\end{array}$ \\
\hline & & $\begin{array}{l}\text { Increased clinical } \\
\text { knowledge from } \\
\text { management of } \\
\text { adverse events }\end{array}$ & $\begin{array}{l}\text { Prevaccinated medical care } \\
\text { teams to care for smallpox } \\
\text { patients }\end{array}$ \\
\hline & & $\begin{array}{l}\text { Increased availability } \\
\text { of vaccinia immune } \\
\text { globulin }\end{array}$ & $\begin{array}{l}\text { Prevaccinated public health } \\
\text { response teams (investigation, } \\
\text { contact tracing, vaccination) }^{\mathrm{d}}\end{array}$ \\
\hline & & $\begin{array}{l}\text { Increase in scientific } \\
\text { knowledge from } \\
\text { studying vaccinees }\end{array}$ & $\begin{array}{l}\text { Better clinical management of } \\
\text { adverse reactions from mass } \\
\text { vaccination }\end{array}$ \\
\hline & & & $\begin{array}{l}\text { Better availability of vaccinia } \\
\text { immune globulin }\end{array}$ \\
\hline \multirow[t]{3}{*}{$\begin{array}{l}\text { General } \\
\text { public }\end{array}$} & $\begin{array}{l}\text { Contact vaccinia } \\
\text { (very low risk) }^{b}\end{array}$ & $\begin{array}{l}\text { Increase in scientific } \\
\text { knowledge from } \\
\text { studying vaccinees }\end{array}$ & $\begin{array}{l}\text { All benefits described } \\
\text { previously }\end{array}$ \\
\hline & \multirow{2}{*}{$\begin{array}{l}\text { Possible decreased trust } \\
\text { in health authorities }\end{array}$} & & Some herd immunity \\
\hline & & $\begin{array}{l}\text { Possible increased trust } \\
\text { in health authorities }{ }^{\mathrm{c}} \\
\text { Deterrent to terrorists }\end{array}$ & $\begin{array}{l}\text { Increased trust in health } \\
\text { authorities }\end{array}$ \\
\hline
\end{tabular}

${ }^{a}$ The informed consent process emphasizes the disclosure of the individual health, employment, and financial risks to the vaccinee.

$\mathrm{b}$ The risk of contact vaccinia will increase as vaccination becomes more widespread among vaccinees not well trained in infection control practices.

${ }^{c}$ The level of trust or mistrust of health authorities will depend on several factors, including how honestly and effectively health officials communicate the risks, benefits, and trade-offs from the different stakeholder perspectives summarized in this table.

${ }^{\mathrm{d}}$ The post-outbreak response benefits from pre-event vaccination could be small if preevent planning, preparedness, and readiness are not optimal. For example, vaccinated but untrained public health response workers would still need to be trained, potentially delaying an effective response. Additionally, efficient post-outbreak mass and ring vaccination could mitigate the risks from lack of pre-event vaccination. 


\section{Once an Outbreak Occurs}

\subsection{CAN WE PREDICT THE DISSEMINATION PATTERNS AND MAGNITUDE OF THE OUTBREAK AT ITS FIRST STAGES? WHAT DATA SHOULD WE QUICKLY COLLECT TO FACILITATE SUCH EMERGENCY MODELING EFFORTS?}

During public health emergencies, such as bioterrorist attacks and disease epidemics, computerized information systems for data management, analysis, and communication may be needed within hours of beginning the investigation. Available sources of data and output requirements of the system may be changed frequently during the course of the investigation. Integrating data from a variety of sources may require entering or importing data from a variety of digital and paper formats. Spatial representation of data is particularly valuable for assessing environmental exposure [10].

One study suggests an approach, which attempts to reduce the complexity of the problem space by finding clusters of similar threats. Because our focus is the design of information systems, the clustering of threats is based on similarities in the functional requirements that each threat imposes on a detection system - threats with similar functional requirements for detection are grouped together. The goal of this approach is to develop a parsimonious and tractable characterization of the problem space for the purpose of surveillance system design, one that will facilitate both design of systems and the associated research in public health surveillance that supports system design. The consequence is that a designer feels confident that as long as clear specifications for detection of one threat in a category are met, the resulting system can detect any threat from the category. The potential advantages of such parsimonious characterization are: (1) focusing more attention on a smaller, but more comprehensive set of threats, (2) identifying equivalent threats that may be more amenable to study because of availability of data, and (3) improving tractability of analysis without, ideally, loss of generality [11].

But even when we attempt to focus at one disease, major uncertainties hinder our ability to reach valid and robust conclusions. In the smallpox case, it is unclear how much residual immunity remains today as a result of past vaccination programs; those vaccinated 25-30 years ago are unlikely to possess complete immunity and a significant proportion may develop less severe forms of the disease, potentially changing the dynamics of transmission. Allowing for past immunity levels is therefore critical when estimating $R_{0}$ from historical data. Historically, most infections occurred in caregivers to symptomatic individuals, whether in households or hospitals 
[3]. It is unclear how 30 years of changes in household sizes, working patterns, and mobility would affect transmission patterns today. Incorporating detailed data on demographics and human mobility into spatially explicit models offers one method by which such extrapolation can be made more reliable, but the scale of changes mean that much uncertainty will inevitably remain. With such uncertainty, it is critical that risk assessment studies use modern statistical methods to obtain the best possible parameter estimates from historical data, while allowing for changes in the last 30 years. However, historical data are less relevant for some key parameters - such as the likely scale of a bioterrorist attack, how rapidly the disease would be recognized, and the ability of public health authorities to respond. Furthermore, it is unclear how population behavior would change in the face of an epidemic. Before recognition of the outbreak, would individuals in the latter stages of prodrome have more or fewer contacts, compared with their historical counterparts? Once smallpox is identified, will people voluntarily restrict their movements, or attempt to flee urban centers? These factors need to be explored with robust analysis of the sensitivity of model results and predicted optimal controls to parameter assumptions [12].

A variety of methods exist for controlling the spread of smallpox, ranging from different vaccination strategies to movement/contact restrictions placed on infectious cases and their contacts. Thus a key aspect of policyorientated epidemic modeling is to assess both the adequacy of current policy and how it might further be optimized. Optimality is principally the minimization of mortality and morbidity, so it is critical that models accurately incorporate expected adverse event rates from vaccination. However, the severe acute respiratory syndrome (SARS) virus has shown that the economic costs of an epidemic can be out of all proportion to the numbers infected, indicating that minimizing the duration of a smallpox outbreak might also be a critical priority when formulating control strategy [12].

\subsection{CAN WE PREDICT THE EFFECT OF INTERVENTIONS DURING AN EVENT? CAN WE TRUST MODELS THAT SUGGEST LIMITED RESPONSE (I.E., TARGETED RATHER THAN MASS VACCINATION FOR SMALLPOX) SHOULD BE SUFFICIENT?}

In every scenario, policymakers must choose between several intervention options for controlling the emerging epidemic. Table 3 by Ferguson et al. summarizes the main options for controlling a smallpox attack [12]. 
TABLE 3. Policy options for controlling smallpox attack [12]

\begin{tabular}{l}
\hline Policy \\
\hline $\begin{array}{l}\text { Quarantine/isolation } \\
\text { Quarantine and isolation of } \\
\text { suspect and confirmed cases }\end{array}$ \\
\\
Movement restrictions \\
For example, quarantine of \\
neighborhoods or closure of \\
schools, airports, or other \\
transport systems
\end{tabular}

"Ring" vaccination

Contacts of suspect smallpox cases are traced and vaccinated when found. Can be coupled with policy of isolation of identified contacts

\section{Targeted vaccination} For example, vaccination of whole population in affected neighborhood or city

\section{Mass vaccination}

Vaccination of whole population of a country experiencing or threatened by an outbreak.

\section{Prophylactic vaccination}

Vaccination before a smallpox release

Benefits Drawbacks

If isolation facilities are adequate, it is highly effective at reducing transmission from known cases

Potentially useful in containing a small outbreak where community transmission is occurring. Used recently to control SARS spread in Hong Kong and Singapore

Minimizes use of vaccine, and hence morbidity and mortality caused by adverse reactions to vaccination

Highly effective during eradication campaign at containing transmission localized to a single geographic area or subpopulation. Reduced vaccine-related mortality. Not dependent on contact tracing

Effective at stopping widespread dissemination of the virus across large areas and protecting individuals from infection. Not dependent on contact tracing

Useful for protecting essential 'first responder' personnel. If used for entire population, very effective at stopping widespread dissemination of virus. Does not have to be implemented quickly. Not dependent on contact tracing
Isolation facilities necessary, or compliance with voluntary policy. Compulsory policies necessarily coercive. Requires rapid detection of cases.

Vaccination certificates issued in the past to prevent potential spread but difficult to assess effectiveness. Costly and difficult to poice, compromised by any illegal movements.

Coercive

Contacts need to be found at an early stage of incubation for vaccine to be effective. Tracing needs to be highly effective to severely limit transmission

Effective when background levels of herd immunity high, but few systematic data on effectiveness in other contexts. Less sparing of vaccine use than ring vaccination. Risk of disease spreading beyond targeted area

Large numbers need to be vaccinated quickly. Might generate unnecessary vaccine-related morbidity and mortality. If policy implemented rapidly, screening for risk factors for adverse reactions might be suboptimal

If used to protect an entire population on an ongoing basis, policy has high, long-term cost, and a large number of probably unnecessary vaccineassociated adverse events would be expected for as long as policy is followed 
When attempting to choose the most appropriate of these response policies prior to an actual event, analyses highlight the importance of beliefs regarding the nature of a bioterrorist attack and response logistics, in addition to disease epidemiology. In the case of smallpox, several examples may be considered. Would an attack be small and controllable through traced vaccination or large enough to require mass vaccination? Would an attack be overt, in which case it could prove possible to respond immediately in a highly targeted fashion and obtain much better results or covert and detected only from symptomatic cases as assumed in this chapter? If traced vaccination was used in response to an attack, would tracing prove accurate and efficient (as documented for a highly unusual natural outbreak that occurred in a Nigerian town) or inaccurate (as suggested by a simulated large attack in a metropolitan area with population 10 million)? Could a rapid mass vaccination campaign be mounted soon enough after an attack occurs and with sufficiently high population coverage to avert most of the second-generation infections, but with care to avoid vaccine complications among those with contraindications? Having never faced a deliberate smallpox attack, there are no empiric answers to questions such as these. In particular, it is an assumption to pretend that parameters such as $R_{0}$ are known, even if estimated on the basis of past outbreaks, because such outbreaks could bear no resemblance to what could occur in a bioterrorist attack [13].

Several models have addressed the issue of choosing the optimal response policy for smallpox outbreak. Table 4 by Ferguson et al. summarizes several of these models, along with the author's views and comments for each of these models [12].

Similar dilemmas exist regarding an anthrax attack. One dilemma is how to rapidly identify such an attack, while preventing false alarms and unnecessary expenditures. The lack of sufficient experience with bioterrorism related pathogens, such as anthrax, might be a leading cause of delay in identifying bioterrorist event due to misdiagnosis. Using risk assessment methods, an effort is made to identify quickly and costeffectively the first cases or exclude a bioterrorist event possibility. The main obstacle that stands in the experts' way is the insufficient existing data on which to rely on [14].

Another dilemma in the case of anthrax, live in evaluating the trade-off between the consequences of antibiotic use and the consequences of failure to treat anthrax poses a dilemma to the treating physician. One study suggests that during influenza season, rapid testing for influenza should be 
TABLE 4. Summary of recent smallpox modeling studies [12]

\begin{tabular}{ll}
\hline Study & Key features \\
\hline Meltzer, M. I., & (1) Homogeneous mixing; \\
Damon, I., LeDuc, & (2) stochastic; (3) no social/ \\
J. W. \& Millar, J. D. & spatial structure; (4) $R_{0}=1.5-3$ \\
Modeling potential & (5) vaccination not directly \\
responses to smallpox & modeled but in conjunction \\
as a bioterrorist & with quarantine is assumed \\
weapon. Emerg. Inf. & to reduce $R$ to below 1; (6) \\
Dis. 7, 959-969 & no depletion of susceptibles; \\
(2001). & (7) 100 people initially \\
& infected
\end{tabular}

Kaplan, E. H., Craft, D. L. \& Wein, L. M. Emergency response to a smallpox attack: The case for mass vaccination. Proc. Natl. Acad. Sci. USA 99, 10935-10940 (2002).
(1) Homogeneous mixing in large population (10 million); (2) deterministic; (3) no social/spatial structure; (4) $R_{0}=3$ for base case (range 1-20); (5) mass vaccination and ring vaccination compared; (6) considers public health logistical constraints; (7) only those "asymptomatic" (that is in prodrome) are infectious - those symptomatic (with rash) are assumed to be isolated; (8) number initially infected $=$ $1-100,000$

Halloran, M. E., (1) Heterogeneous mixing Longini, I. M., Nizam, (social structure included) in A. \& Yang. Y. Containing bioterrorist smallpox. Science 298, 1428-1432 (2002).

\section{Comments}

(1) Estimates required control effort by correlating vaccine doses used ; against number of cases in historical outbreaks; (2) number of doses is not related to the number of cases, but to the level of susceptibility (and $R_{0}$ ); (3) model substantially overestimates cases because depletion of susceptibles is not modeled;(4) controls assumed to reduce $R$ to 0.99 , that is, program effectiveness is model input

\section{(1) $R_{0}$ assumed derived from} historical estimates, but level of prodromal transmission assumed much greater than new best estimates derived from historical data $^{21} ;(2)$ assumption that transmission occurs during the prodromal period biases results in favor of mass vaccination; (3) assumption of homogeneous mixing will also bias the results in favor of mass vaccination; (4) considers vaccine-related deaths only in contraindicated people, and not those in noncontraindicated individuals or other adverse events

(1) Large number of parameters assumed, particularly regarding mixing patterns, limited sensitivity analysis performed; (2) relatively large proportion $(0.05-0.5 \%)$ of community initially infected; (3) model of small community of 2,000 individuals; (4) assumption that $>75 \%$ of transmission occurs during prodrome biases results in favor of mass vaccination

Bozzette, S. A. et al. A model for a smallpox-vaccination policy. N. Engl. J. Med. 348, 416-425 (2003). stochastic; (3) $R_{0}=3.2 ;$; (4) mass vaccination and ring vaccination compared; (5) considers current residual herd immunity; (6) number initially infected $=1-10$

(1) Homogeneous mixing; (2) stochastic; (3) $R$ (no control) $=15,3.4$ and 1.8 in hospital, mixed and community outbreaks respectively; ( $R_{0} \geq R$ (no control)); (4) compares mass vaccination, ring vaccination and prophylactic vaccination of healthcare workers; (5) considers vaccine-related adverse events; (6) number initially infected $=2-100,000$
(1) Assumes the effect of the control policies on $R$, based on review and "judgment"; that is, effectiveness of policies is an input into the model rather than an output; the model therefore has little explanatory or predictive power; (2) large number of parameters assumed, limited sensitivity analysis performed; (3) assumes disease has no effect on the depletion of susceptibles; (4) assessment of threat of attack is subjective 
performed in symptomatic patients, followed by empiric treatment for anthrax, pending blood culture results for those who test negative for influenza [15].

\subsection{HOW DIFFERENT SHOULD INTENTIONALLY DISTRIBUTED SMALLPOX BE COMPARED TO NATURALLY OCCURRING SMALLPOX OUTBREAKS IN THE PAST?}

If an attack occurs in the near future, it is unlikely that a genetically modified strain of variola would be used. However, if the strain is genetically modified to increase its virulence, possible consequences could be even more dramatic. Unfortunately, scientific advancements over the last two decades have made it possible to develop genetically altered strains of orthopoxviruses [16].

Genetic engineering of viruses has become a common practice. One major objective of genetic manipulation is to use engineered viral vectors for the delivery of genetic information with therapeutic intent or to modify viruses so as to alter the host's immune response. Changes in virulence and host range of modified viruses are generally hard to predict. However, when one studies the possibility of making variola virus more pathogenic, the research and development (R\&D) work will most likely be focused on targets such as:

1. Shortening the incubation period of the disease by improving the attachment of the virus to a host cell and accelerating virus propagation in host cells

2. Reducing the infectious dose and increasing mortality by the suppression/subversion of innate and specific immune responses to the virus

3. Strengthening the severity, "adding" new syndromes of infection and increasing mortality by widening the number of potential sites of infection (e.g., brain and parenchymal organs).

These are just some of the possible targets of genetic engineering procedures. However, even if such work is underway in some countries, it is obvious that we would never obtain any "official" information on the work with variola virus to increase its virulence by inserting alien genes. At the same time, we need to know what and how this genetic engineering work could be performed in order to understand what protection we must develop against genetically engineered variola virus [16]. 


\subsection{HOW SUSCEPTIBLE IS THE POPULATION TODAY TO SMALLPOX?}

Routine smallpox vaccination program in Israel instituted in 1949, included vaccine administration to (i) infants aged 1 year, (ii) children (aged 9-10 years), (iii) military recruits (aged 18 years), and (iv) new immigrants. After the World Health Organization (WHO) declaration on the eradication of smallpox in 1979, routine smallpox vaccination in Israel was officially discontinued in July 1980. Army recruits continued to receive smallpox vaccination until July 1996. A first responder revaccination campaign began on September 2002 and as of May 2003, some 22,000 doses have been administered [17].

Data collected during the eradication campaign showed that neutralizing antibodies to smallpox are persistent and may be detected 20 years or more after vaccination [18]. More recent studies reported that after two revaccinations, the antibody levels to vaccinia persist and may provide a sufficient level of immunity for 30-75 years [19, 20]. Similar conclusions were drawn by Crotty and his group. They have studied long-term B cell memory after smallpox vaccination in a previously ( 3 months to 60 years) vaccinated group. Their results demonstrated initial exponential decay of memory B cells, with a half-life of $<1$ year, followed by a plateau $\sim 10$-fold lower than peak that is stably maintained for $>50$ years after vaccination [21]. Several studies also demonstrated that memory CD4+ and CD8+ Tcells to vaccinia antigen persist from months to decades after last smallpox revaccination [20-24]. Hsieh et al. showed that healthy subjects who were vaccinated within the last three decades and had a visible vaccination scar had remarkable T-cell reactivity compared to people who did not have a scar, or were vaccinated more than four decades ago [25].

Yet, the clinical significance of these studies in terms of protection against variola infection is not clear, and the exact level of immunity in the population today, 10-35 years after termination of continuous vaccination campaigns, is largely unknown.

\section{Reference}

1. Zilinskas RA, Hope B, North DW. A discussion of findings and their possible implications from a workshop on bioterrorism threat assessment and risk management. Risk Anal 2004; 24(4):901-908.

2. Haas $\mathrm{CN}$. The role of risk analysis in understanding bioterrorism. Risk Anal 2002; 22(4):671-677. 
3. Kwik G, Fitzgerald J, Inglesby TV, O'Toole T. Biosecurity: responsible stewardship of bioscience in an age of catastrophic terrorism. Biosecur Bioterror 2003; 1(1):27-35.

4. Atlas R, Campbell P, Cozzarelli NR, Curfman G, Enquist L, Fink G, et al. Statement on the consideration of biodefence and biosecurity. Nature 2003; 421(6925):771.

5. Sidel VW. Bioterrorism in the United States: a balanced assessment of risk and response. Med Confl Surviv 2003; 19(4):318-325.

6. Aragon TJ, Fernyak SE. The risks and benefits of pre-event smallpox vaccination: where you stand depends on where you sit. Ann Emerg Med 2003; 42(5):681-684.

7. Anand P. Public health. Decision-making when science is ambiguous. Science 2002; 295(5561):1839.

8. Karwa M, Currie B, Kvetan V. Bioterrorism: preparing for the impossible or the improbable. Crit Care Med 2005; 33(1 Suppl):S75-95.

9. Bozzette SA, Boer R, Bhatnagar V, Brower JL, Keeler EB, Morton SC, et al. A model for a smallpox-vaccination policy. N Engl J Med 2003; 348(5): 416-425.

10. Zubieta JC, Skinner R, Dean AG. Initiating informatics and GIS support for a field investigation of bioterrorism: the New Jersey anthrax experience. Int J Health Geogr 2003; 2(1):8.

11. Wagner MM, Dato V, Dowling JN, Allswede M. Representative threats for research in public health surveillance. J Biomed Inform 2003; 36(3):177-188.

12. Ferguson NM, Keeling MJ, Edmunds WJ, Gani R, Grenfell BT, Anderson RM, et al. Planning for smallpox outbreaks. Nature 2003; 425(6959):681-685.

13. Kaplan EH. Preventing second-generation infections in a smallpox bioterror attack. Epidemiology 2004; 15(3):264-270.

14. Schultz CH. Chinese curses, anthrax, and the risk of bioterrorism. Ann Emerg Med 2004; 43(3):329-332.

15. Fine AM, Wong JB, Fraser HS, Fleisher GR, Mandl KD. Is it influenza or anthrax? A decision analytic approach to the treatment of patients with influenza-like illnesses. Ann Emerg Med 2004; 43(3):318-328.

16. Alibek K. Smallpox: a disease and a weapon. Int J Infect Dis 2004; 8 (2 Suppl):S3-8.

17. Orr N, Forman M, Marcus H, Lustig S, Paran N, Grotto I, et al. Clinical and immune responses after revaccination of Israeli adults with the Lister strain of vaccinia virus. J Infect Dis 2004; 190(7):1295-1302.

18. Fenner F, World Health Organization. Smallpox and its eradication. Geneva: World Health Organization, 1988.

19. el-Ad B, Roth Y, Winder A, Tochner Z, Lublin-Tennenbaum T, Katz E, et al. The persistence of neutralizing antibodies after revaccination against smallpox. J Infect Dis 1990; 161(3):446-448. 
20. Hammarlund E, Lewis MW, Hansen SG, Strelow LI, Nelson JA, Sexton GJ, et al. Duration of antiviral immunity after smallpox vaccination. Nat Med 2003; 9(9):1131-1137.

21. Crotty S, Felgner P, Davies H, Glidewell J, Villarreal L, Ahmed R. Cutting edge: long-term B cell memory in humans after smallpox vaccination. J Immunol 2003; 171(10):4969-4973.

22. Littaua RA, Takeda A, Cruz J, Ennis FA. Vaccinia virus-specific human CD4+ cytotoxic T-lymphocyte clones. J Virol 1992; 66(4):2274-2280.

23. Demkowicz WE, Jr., Littaua RA, Wang J, Ennis FA. Human cytotoxic T-cell memory: long-lived responses to vaccinia virus. J Virol 1996; 70(4):26272631.

24. Frelinger JA, Garba ML. Responses to smallpox vaccine. N Engl J Med 2002; 347(9):689-690.

25. Hsieh SM, Pan SC, Chen SY, Huang PF, Chang SC. Age distribution for T-cell reactivity to vaccinia virus in a healthy population. Clin Infect Dis 2004; 38(1):86-89. 